\title{
The Synthesis of Bio-Polyol from Epoxidized Soybean Oil
}

\author{
Nguyen Thi Thuy ${ }^{*}, \mathrm{Vu}$ Minh Duc, Nguyen Thanh Liem \\ Polymer centre, Hanoi University of Science and Technology, 1 Dai Co Viet, Hanoi, Vietnam
}

Received 20 July 2017

Revised 09 October 2017; Accepted 19 October 2017

\begin{abstract}
Hydroxyl and oxirane functionality were calculated from molecular weight and hydroxyl or oxirane-oxygen content of polyol. The effect of reaction parameters like the amount of reagents, catalyst, temperature and time on a polyol synthesis was studied through the hydroxyl and oxirane functionality of product. Moreover, the impact of the parameters on the selectivity of catalyst was determined by comparing a polyol yield to an epoxide ring opening yield. When the hydroxylation reaction was carried out with ESO: $\mathrm{H}_{2} \mathrm{O}$ molar ratio of $1: 15$; in 8 wt. $\%$ of $\mathrm{H}_{2} \mathrm{SO}_{4}$; at temperature of $70^{\circ} \mathrm{C}$ and in 5 hours, the polyol yield of reaction was $70.32 \%$ and the hydroxyl functionality of polyol reached to 5.63 .
\end{abstract}

Keywords: Epoxidized soybean oil, biopolyol, nucleophile, epoxide ring-opening.

\section{Introduction}

Today, epoxidized vegetable oils are very interesting because they are not only environmentally friendly but also be produced from natural renewable sources. Application areas of the epoxidized vegetable oil is also very diverse. They can be used as a lubricant, sealing substances, surfactant, plasticiser for polymers, resin for materials of polymer composite or coatings, adhesives. On the other hand, due to the high activity of the oxirane ring the epoxidized vegetable oil also plays role as raw material for the synthesis of organic compounds including synthesis of biopolyol [1].

Due to the polarity of $\mathrm{C}-\mathrm{O}$ bonds, the electron deficient carbon atom of oxirane constitutes an active site for nucleophilic

\footnotetext{
*Corresponding author. Tel.: 84-904505335.

Email: thuy.nguyenthi1@.hust.edu.vn

https://doi.org/10.25073/2588-1140/vnunst.4511
}

reactions while the electron rich oxygen atom can afford an electronphilic reaction site [2]. The reagent and catalyst for the hydroxylation epoxidized vegetable oil are diversified. In 2012, Synvain Caillol investigated to synthesis of new polyester polyols from epoxidized vegetable oils and bio-based acids [3]. In 2013, Norhayati Mohd Noor carried out the synthesis of palm-based polyols by using catalyst of K10 montmorillorit [4]. In 2015, Jing Zhang synthesized polyols from ring-opening epoxidized soybean oil reaction by a Castor Oil-based Fatty Diol [5].

Water is considered to be the source of available, inexpensive and completely environmentally friendly materials. Using water as reactive agents for the modified process of epoxidized soybean oil into biopolyol will bring many benefits. This work studied the influence of reactive reagent content of $\mathrm{H}_{2} \mathrm{O}$, catalyst content of $\mathrm{H}_{2} \mathrm{SO}_{4}$ as well as temperature and reaction time on the hydroxylation process to 
find the optimal conditions to synthesize biopolyol of high hydroxyl functionality.

\section{Experiment}

\subsection{Materials}

Wijs solution were purchased from a Merck, Gemany. Hydrogen bromide solution (33 wt.\%) was obtained from a Sigma-Aldrich, USA. Epoxidized soybean oil (ESO) (table 1) and acid sulfuric (98 wt.\%) glacial acetic acid were obtained from Xilong Chemical, China.

Table 1. Characteristics of ESO and biopolyol

\begin{tabular}{lll}
\hline Characteristics & ESO & Biopolyol \\
\hline Hydroxyl functionality & $0.32^{*}$ & $5.63^{*} / 5.60^{*}$ \\
Oxirane functionality & $3.56^{*}$ & $0.44^{*} / 0.44^{*}$ \\
Iodine value, $\mathrm{cgI}_{2} / \mathrm{g}$ & 3.00 & 2.87 \\
Density $20^{\circ} \mathrm{C}, \mathrm{g} / \mathrm{ml}$ & 0.99 & 1.02 \\
$\mathrm{Viscosity} 20^{\circ} \mathrm{C}, \mathrm{cP}$ & 700 & 1920 \\
$\mathrm{Mw}$ & $920.17^{*}$ & $970.54^{*}$ \\
$\left(^{*} \mathrm{GPC},{ }^{* *}\right.$ calculate $)$ & $965.30^{* *}$ \\
\hline
\end{tabular}

\subsection{Methods}

\subsubsection{Hydroxylation procedure}

The reaction is performed in a $500 \mathrm{ml}$ three neck flask equipped with a stirrer, thermometer and reflux cooler., The epoxidized soybean oil, reagent of $\mathrm{H}_{2} \mathrm{O}$ and catalyst of $\mathrm{H}_{2} \mathrm{SO}_{4}$ were added to this flask. After charging, the reaction continued by mixing at certain temperature for a further time. After that, the mixture was cooled down and neutralized by water. The final product was dried out by heating about $60^{\circ} \mathrm{C}$ in a vacuum oven.

\subsubsection{Analytical techniques}

Fourier transform Infrared spectroscopic analysis and nuclear magnetic resonance spectroscopic analysis were performed on the IRAffiniti-1S, Shimadzu (Japan) and Bruker Avance 500 (USA). The molecular weight of sample was analyzed by using Shimadzu 20A (Japan) with column TSK gel G60000HXL and dectector RID 10D. The density and viscosity are determined by using pycnometer $25 \mathrm{ml}$ (China) and Brookfield Model RVT (Germany) respectively. Iodine value, oxirane oxygen content and hydroxyl content are determined according to standard ASTM D5768, D1652 and D1957 respectively.

\section{Results}

\subsection{Evaluating the result of hydroxylation reaction}

The success of the hydroxylation reaction associated with the formation of hydroxyl groups on macromolecule of the product. The FTIR spectroscopic analysis of obtained polyol and ESO were studied to confirm the presence of hydroxyl groups on macromolecules.

FTIR spectrum of ESO and polyol are shown in fig.1. The disappearance of the band at $820.47 \mathrm{~cm}^{-1}$ in spectra of polyol shown that the epoxide group had been used up. The appearance of the band at $3417.86 \mathrm{~cm}^{-1}$, which was not seen in spectra of ESO, was characteristic of the hydroxyl group that connected with carbon atom. This analytic results confirmed that the hydroxylation reaction had taken place.

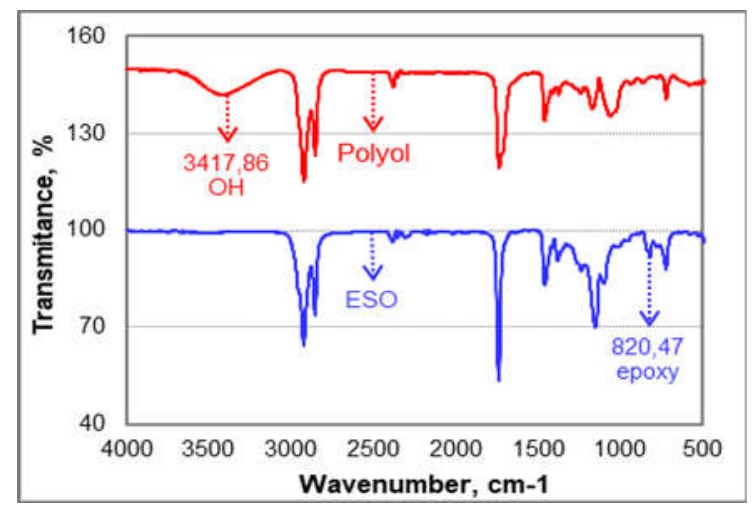

Polyol (ESO: $\mathrm{H}_{2} \mathrm{O}-1: 15 ; \mathrm{H}_{2} \mathrm{SO}_{4}-8 \mathrm{wt} . \% ; 70^{\circ} \mathrm{C}$ )

Fig. 1. FTIR spectrum of ESO and polyol. 
A pair of the ESO and other polyol were analysed by nuclear magnetic resonance spectroscopy and the results are shown in fig. 2 .

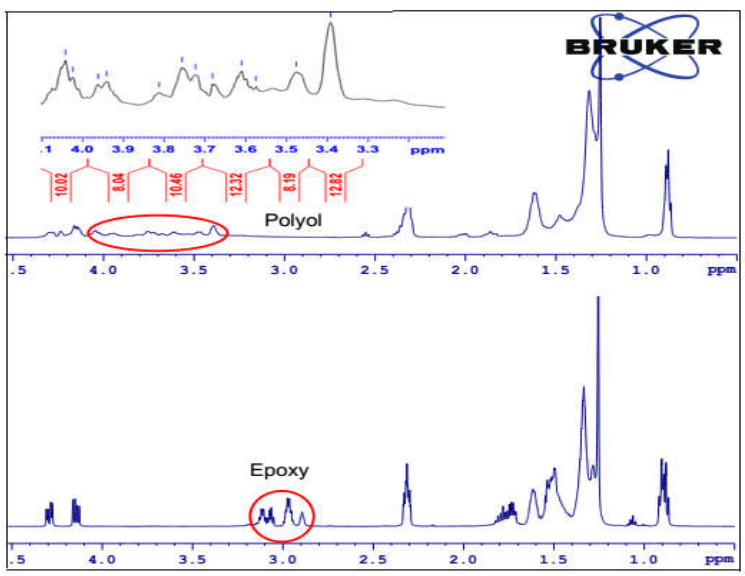

Polyol (ESO: $\mathrm{H}_{2} \mathrm{O}-1: 20 ; \mathrm{H}_{2} \mathrm{SO}_{4}-8 w t \% ; 70^{\circ} \mathrm{C}$ )

Fig. 2. H-NMR spectrum of ESO and polyol

As can be seen from fig.2, the peaks at 2.9 $\div 3.3 \mathrm{ppm}$ which correspond to signature of epoxide groups protons existed clearly on the H-NMR spectra of the ESO but these peaks did not appear on H-NMR spectra of the polyol. It demonstrated the epoxide groups in the ESO has been changed. Simultaneously the peaks at $3.4 \div 4.1 \mathrm{ppm}$ assigned to the methylinic protons $(\mathrm{HC}-\mathrm{OH})$ and the protons associated with the hydroxyl group which connected to carbon atom $(\mathrm{HC}-\mathrm{OH})$ were absent from the $\mathrm{H}$ NMR spectra of the ESO but appeared on $\mathrm{H}$ NMR spectra of the polyol. This proves the epoxide groups in the ESO were converted to hydroxyl groups in the polyol. The result of nuclear magnetic resonance spectroscopic analysis once again confirmed the success of hydroxylation reaction.

\subsection{The impact of reaction parameters on the hydroxylation reaction}

It is easy to calculate theoretical hydroxyl content of the polyol $(434.77 \mathrm{mgKOH} / \mathrm{g})$ from the oxirane-oxygen content of ESO (6.2\%). The polyol yield $(\mathrm{P})$ and the epoxide ring-opening yield (E) are calculated by using formulas of (1) and (2) with exp: experiment; th: theory; $\mathrm{OH}$ : hydroxyl; Oxo: oxirane oxygen.

$$
\begin{gathered}
\mathrm{P}=\frac{\mathrm{OH} \text { content }_{\mathrm{exp}}-19.85}{\mathrm{OH} \text { content }_{\mathrm{th}}} \times 100 \\
\mathrm{E}=\frac{6.2-\text { Oxo content }_{\mathrm{exp}}}{6.2} \times 100
\end{gathered}
$$

The functionality of a polymer is the number of functional-group mole in one mole of polymer. It is calculated from the functionalgroup content and molecular weight of the polymer. The oxirane-functionalities of the ESO and polyol are calculated by using formulars of (3) and (4). The hydroxylfunctionality of polyol are calculated by using formular of (5).

$$
\begin{aligned}
\mathrm{Ox}_{\mathrm{ESO}} & =\frac{\mathrm{M}_{\mathrm{ESO}} \times \mathrm{Oxo} \text { content }_{\mathrm{ESO}}}{16 \times 100} \\
\mathrm{Ox} \#_{\text {polyol }} & =\frac{\mathrm{M}_{\text {polyol }} \times \text { Oxo content }_{\text {polyol }}}{16 \times 100} \\
\mathrm{OH} \#_{\text {polyol }} & =\frac{\mathrm{M}_{\text {polyol }} \times \mathrm{OH}_{\text {content }}}{56.11 \times 100}
\end{aligned}
$$

In which, the molecular weight of polyols are calculated from the molecular weight of ESO and the increased weight when the epoxide group converted into two hydroxyl groups.

$\mathrm{M}_{\mathrm{polyol}}=\mathrm{M}_{\mathrm{ESO}}+\frac{\mathrm{Ox}_{\mathrm{ESO}} \times \mathrm{P} \times(17 \times 2-16)}{100}$

\subsubsection{The effect of water content}

A series of hydroxylation reactions were carried out at $70^{\circ} \mathrm{C}$ temperature, 8 wt. $\%$ of $\mathrm{H}_{2} \mathrm{SO}$, the molar ratio epoxide group of ESO and water $\left(\mathrm{ESO}: \mathrm{H}_{2} \mathrm{O}\right)$ in the range of $1: 10$ to $1: 20$. Progress of reaction was monitored by measurement of the oxirane-oxygen content and the hydroxyl content of products of the reaction. 
The oxirane funtionality of polyol declined and the hydroxyl functionality increased with the prolonging reaction time. When raising the amount of $\mathrm{H}_{2} \mathrm{O}$ from molar ratio of $1: 10$ to $1: 15$, the oxirane funtionality of polyol decreased, indicating that the ability to open epoxide ring increased and consequently the hydroxyl functionality of polyol grew strongly as well (fig.3).

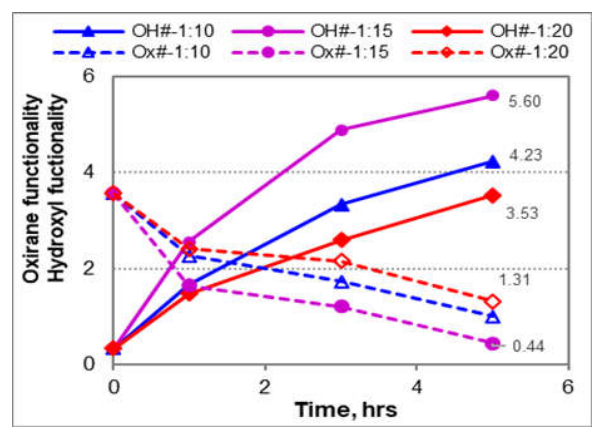

Fig. 3. The effect of $\mathrm{H}_{2} \mathrm{O}$ content on the oxirane and hydroxyl functionality of polyol.

Increasing further the amount of $\mathrm{H}_{2} \mathrm{O}$ to $1: 20$, the oxirane funtionality of polyol had the greate value than the reactions with molar ratio of $1: 10$ and $1: 15$. That proved the ability to open the epoxide ring in this case was the lowest. The obviously result of hydroxyl functionality of the polyol in this case also followed the same trend (fig.3). After five hours reaction with $\mathrm{H}_{2} \mathrm{O}$ content of 1:15 molar ratio, the hydroxyl functionality of obtained polyol was 5.6.

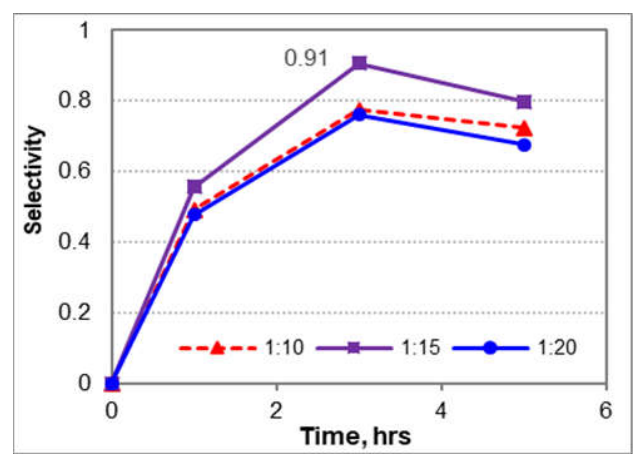

Fig.4. The effect of $\mathrm{H}_{2} \mathrm{O}$ content on the selectivity of catalyst.
The selectivity of catalyst $(\mathrm{P} / \mathrm{E})$ is evaluated based on the amount of formed hydroxyl group and the amount of ring-opened epoxide group. The comparison between a polyol yield and an epoxide ring-opening yield is necessary to determine the selectivity of catalyst. The selectivity of catalyst was calculated from the experimental hydroxyl and oxirane-oxygen content of polyol and using formulas (1) and (2). The results are presented in fig. 4.

It is found that, along with the prolongation of reaction time, the selectivity of catalyst increased and reached to the maximum value at three hours and then decreased with further increase in reaction time.

With the low or high content of $\mathrm{H}_{2} \mathrm{O}$, the selectivities of catalyst were nearly the same and much lower than that of the $\mathrm{H}_{2} \mathrm{O}$ content of $1: 15$. The highest of selectivity is 0.91 at three hours reaction with molar ratio ESO: $\mathrm{H}_{2} \mathrm{O}$ of 1:15 (fig.4). Thus, the molar ratio ESO: $\mathrm{H}_{2} \mathrm{O}$ of 1:15 showed either the largest ability to form the hydroxyl group or the highest selectivity of catalyst, indicating that this reaction had the lowest degree of site reactions.

\subsubsection{The effect of catalyst content}

Three hydroxylation reactions were carried out at $70^{\circ} \mathrm{C}$ temperature, the ratio of ESO: $\mathrm{H}_{2} \mathrm{O}$ was fixed at 1:15 and concentration of catalyst $\mathrm{H}_{2} \mathrm{SO}_{4}$ changed from 6 to $10 \mathrm{wt}$.\%. Progress of reaction was monitored by measurement of the oxirane-oxygen content and the hydroxyl content of products of the reaction.

At one hour reaction, the oxirane fuctionality of polyols when $8 \mathrm{wt} . \%$ or $10 \mathrm{wt} . \%$ of catalyst was used were nearly the same and lower than that of polyol with catalyst of 6 wt.\%. That mean, the ability to open epoxide ring increased when the catalyst content raised from 6 wt. $\%$ to 8 wt. $\%$ but did not change much with further increase in content of catalyst. However, at three hours reaction, the oxirane functionality of polyols were equal so the catalyst content did not impact much on the ability to open epoxide ring. The reaction time is prolonged to five hours, the ability to open 
epoxide ring with 8 wt.\% catalyst was little higher than that of another catalyst content (fig.5).

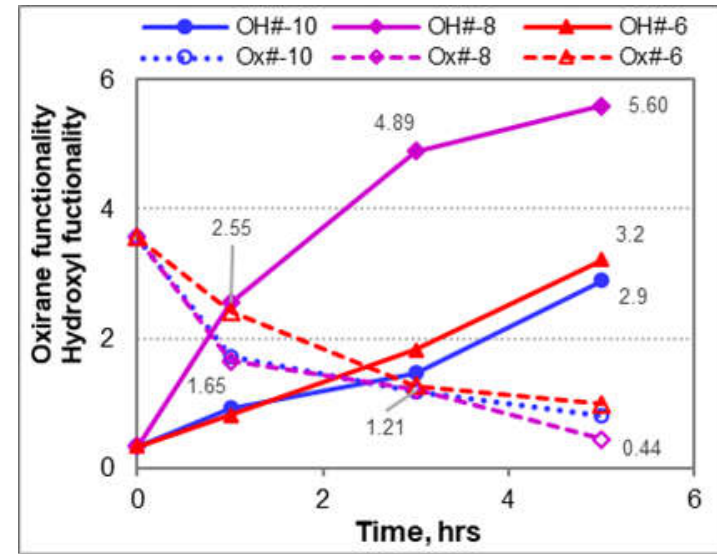

Fig. 5. The effect of $\mathrm{H}_{2} \mathrm{SO}_{4}$ content on the oxirane and hydroxyl funtionality of polyol.

The catalyst content influenced not much the ability to open epoxide ring whereas it impacted great on the ability to form hydoxyl group (fig.5). With the small (6 wt.\%) or large (10 wt.\%) catalyst content, the hydroxyl functionality of polyols was not much different but very smaller than that of polyol with $8 \mathrm{wt} . \%$ catalyst, indicating that 8 wt.\% catalyst promoted the ability to form hydroxyl group.

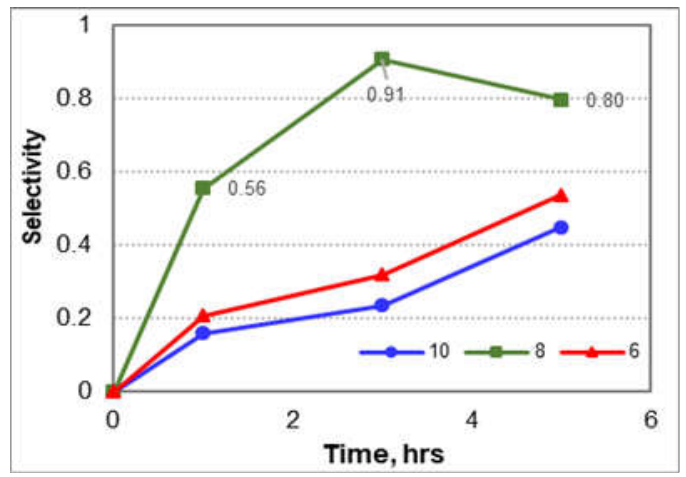

Fig. 6. The effect of $\mathrm{H}_{2} \mathrm{SO}_{4}$ content on the selectivity of catalyst.
With all catalyst contents, the ability to open epoxide ring were not much different whereas the ability to form hydroxyl group with $6 \mathrm{wt} . \%$ and $10 \mathrm{wt} . \%$ catalyst was low, therefore the selectivity of catalyst in these cases was small and increasing with the prolongation of reaction time (fig.6). However, 8 wt.\% catalyst was the most suitable medium for the formation of hydroxyl group, as a result the selectivity of catalyst in this case was large.

As can be noticed from fig.5, the hydroxyl functionality of polyol was 2.55 at one hour reaction and raised quickly to 4.89 at three hours reaction (1.9 times higher than that of one hour reaction) and then increased slowly to 5.60 at five hours reaction. Whereas, oxirane fuctionality of polyol decreased from 1.65 (at one hour reaction) to 1.21 (at three hours reaction) and reduced more quickly to 0.44 (at five hours reaction) (fig.5). Accordingly that, the selectivity of catalyst with 8 wt. $\%$ catalyst increased fast from 0.56 at one hour reaction to 0.91 at three hours reaction and decreased 0.8 at five hours reaction (fig.6).

\subsubsection{The effect of temperature reaction}

A series of hydroxylation reactions were carried out at $60^{\circ} \mathrm{C}, 70^{\circ} \mathrm{C}$ and $80^{\circ} \mathrm{C}$ temperature, the molar ratio of ESO: $\mathrm{H}_{2} \mathrm{O}$ and the concentration of catalyst $\mathrm{H}_{2} \mathrm{SO}_{4}$ were fixed at $1: 15$ and 8 wt.\%. Progress of reaction was monitored by measurement of the oxiraneoxygen content and the hydroxyl content of products of the reaction.

The hydroxylation reaction is carried out at temperature of $60^{\circ} \mathrm{C}$, the ability to open epoxide ring and to form hydroxyl group were small. The temperature of reaction extended to $70^{\circ} \mathrm{C}$, the ability to open epoxide ring increased. However, oxirane functionality of polyols with $70^{\circ} \mathrm{C}$ or $80^{\circ} \mathrm{C}$ was not different therefore the ability to open epoxide ring nearly did not grow with further increase in temperature. Unlike oxirane functionality, the ability to form hydroxyl group at one hour reaction with $80^{\circ} \mathrm{C}$ (3.15) was higher than that of with $70^{\circ} \mathrm{C}(2.55)$ (fig.7), for this reason the selectivity of catalyst 
at one hour reaction with $80^{\circ} \mathrm{C}(0.68)$ was also higher than that of with $70^{\circ} \mathrm{C}(0.56)$ (fig. 8$)$. The reaction time was prolonged to three hours or five hours, the ability to form hydroxyl group with $70^{\circ} \mathrm{C}$ was higher than that of with $80^{\circ} \mathrm{C}$, correspondingly the selectivity of catalyst at three hours reaction with $70^{\circ} \mathrm{C}(0,91)$ was bigger than that of with $80^{\circ} \mathrm{C}(0.87)$ (fig.8).

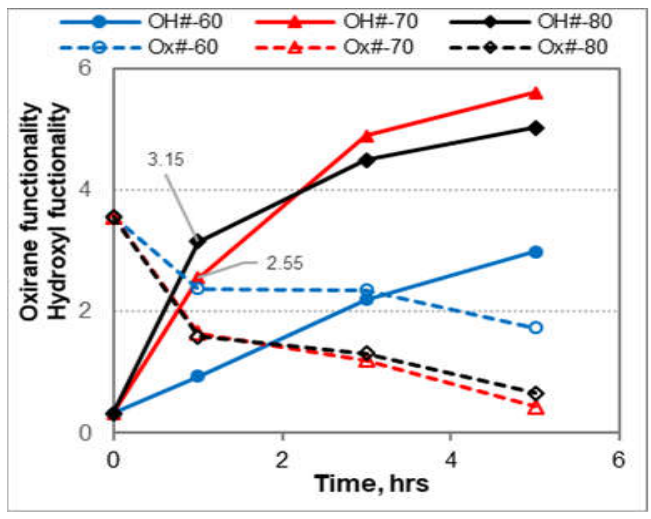

Fig. 7. The effect of temperature on the oxirane and hydroxyl funtionality of polyol.

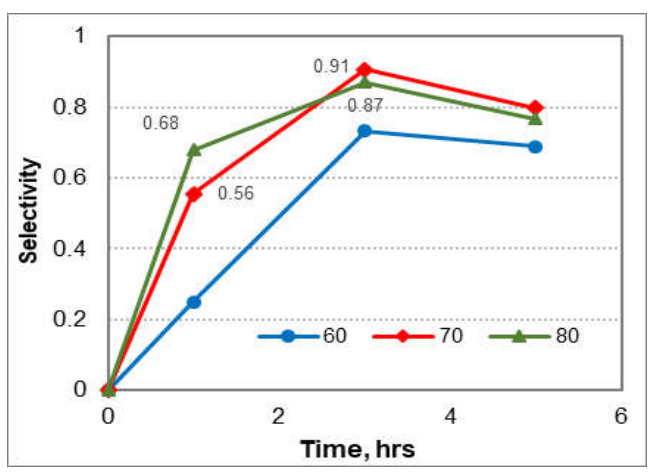

Fig. 8. The effect of temperature on the selectivity of catalyst.

With three reaction temperature, the oxirane functionality of polyol declined strongly in the first hour reaction and slightly in two hours following and little strongly in more two hours next. Whereas, the hydroxyl functionality of polyol had trend of increasing slowlier when the reaction time is prolonged from three to five hours (fig.7), consequently that, the selectivity of catalyst always reached to maximum value at three hours reaction (fig.8).

\subsubsection{The effect of reaction time}

The hydroxylation reaction is carried out in nine hours at $70^{\circ} \mathrm{C}$ temperature, the molar ratio of ESO: $\mathrm{H}_{2} \mathrm{O}$ and the concentration of catalyst $\mathrm{H}_{2} \mathrm{SO}_{4}$ were fixed at 1:15 and $8 \mathrm{wt} . \%$. Progress of reaction was monitored by measurement of the oxirane-oxygen content and hydroxyl content of products of the reaction. The selectivity of catalyst was calculated from the polyol yield and epoxide ring-opening yield.

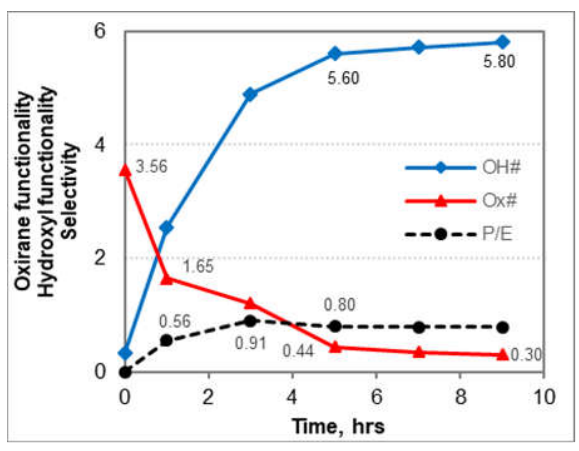

Fig. 9. The effect of time on the oxirane and hydroxyl functionality of polyol and the secletivity of catalyst.

As can be seen from fig.9, the oxirane functionality of polyol dropped strongly from 3.56 to 1.65 at one hour reaction and continued to go down 0.44 at five hours reaction but decreased very slowly to 0.30 when further prolonging the reaction up to nine hours. The corresponding to the oxirane functionality, the hydroxyl functionality of polyol raised to 5.60 at five hours and increased very slowly to 5.8 when further extending the reaction up to nine hours. Thus, after five hours both the epoxide ring-opening reaction and the hydroxyl group forming reaction took place very slowly.

The selectivity of catalyst obtained 0.56 at one hour reaction and increased to 0.91 at three hours but went down 0.80 at five hours and remained unchanged up to nine hours. 


\section{Conclusion}

The success of hydroxylation reaction of epoxidized soybean oil is confirmed by FTIR and H-NMR spectrum.

The optimal conditions for the hydroxylation reaction of epoxidized soybean oil was found: the ESO: $\mathrm{H}_{2} \mathrm{O}$ molar ratio of $1: 15$, the $\mathrm{H}_{2} \mathrm{SO}_{4}$ of $8 \mathrm{wt} \%$, at temperature of $70^{\circ} \mathrm{C}$.

The hydroxylation reaction of epoxidized soybean oil was carried out in five hours, the polyol yield and the epoxide ring-opening yield are $70.32 \%$ and $88.17 \%$ respectively. The hydroxyl functionality of bio-polyol in case reached to $5.63^{*} / 5.60^{* *}$ and another characteristics of this bio-polyol were shown in table 1 .

\section{Acknowledgements}

This work was supported by Polymer \& Composite of Key-Laboratory, Hanoi University of Science and Technology, Project T2016-PC-011

\section{References}

[1] Nikesh B. Samarth, Prakash A. Mahanwar, Modified Vegetable Oil Based Additives as a Future polymeric Matterial - Review, Open Journal of Organic Polymer Materials, 5 (2005), $1-22$

[2] J. D. Earls, J. E. White, L. C. López, Z. Lysenko, M. L. Dettloff and M. J. Null, Analysing the Temperature Effect on the Competitiveness of the Amine Addition versus the Amidation Reaction in the Epoxidized Oil/Amine System by MCR-ALS of FTIR Data, Polymer, 48 (2007), 712-719

[3] Sylvain Caillol, Myriam Pesroches, Gilles Bontevin, Cédric Loubat, Rémi Auvergne and Bernard Boutevin, Synthesis of new Polyester polyols from epoxidized vegetable oils and biobased acids, Eur. J. Lipid Sci. Technol., V.114 (2012), 1447-1459,.

[4] Norhayati Mohd Noor, Tuan Noor Maznee Tuan Ismail, Yeong Shoot, Kian and Hazimah Abu, Hassan, Synthesis of Palm-based polyols: effect of K10 montmorillorite catalyst, Journal of Oil Palm Research, V.25(1) (2013), 92-99

[5] Jing Zhang, Ji Jun Tang, and Jiao Xia Zhang, Polyols prepared from Ring-opening Epoxidized Soybean Oil by a Castor Oil-based Fatty Diol, International Journal of Polymer Science, Volume 2015, 8 pages.

\title{
Tổng hợp bio-polyol từ dầu đậu nành epoxy hóa
}

\author{
Nguyễn Thị Thủy, Vũ Minh Đức, Nguyễn Thanh Liêm \\ Trung tâm Nghiên cúu vật liệu polyme, Truờng Đại học Bách khoa Hà Nội, \\ 1 Đại Cồ Việt, Hà Nọi, Việt Nam
}

Tóm tắt: Từ khối lượng phân tử và hàm lượng nhóm chức có thể xác định được chức hydroxyl và chức oxiran của polyol. Ảnh hưởng của các thông số như hàm lượng tác nhân phản ứng, hàm lượng xúc tác, nhiệt độ và thời gian phản ứng tới phản ứng tổng hợp bio-polyol được nghiên cứu thông qua chức hydroxyl và chức oxiran của sản phẩm. Bằng việc đánh giá hiệu suất polyol hóa so với hiệu suất mở vòng nhóm epoxy cũng thấy được ảnh hưởng của các tác yếu tố trên tới độ chọn lọc của xúc tác. Khi thực hiện quá trình polyol hóa với tỉ lệ mol ESO/ $\mathrm{H}_{2} \mathrm{O}: 1 / 15 ; \mathrm{H}_{2} \mathrm{SO}_{4} 8 \%$, nhiệt độ $70^{\circ} \mathrm{C}$ trong 5 giờ phản ứng, hiệu suất polyol hóa đạt $70.32 \%$ và sản phẩm bio-polyol có chức hydroxyl đạt 5.63.

Tù khóa: Dầu đậu nành epoxy hóa, bio-polyol, nucleophin, mở vòng epoxy hóa. 